City University of New York (CUNY) CUNY Academic Works

2017

\title{
An Examination of "Lookism" in Scholarly Literature
}

Diana Saiki

Ball State University

Alyssa Dana Adomaitis

New York City College of Technology

Gundlach Jessica

Ball State University

\section{How does access to this work benefit you? Let us know!}

More information about this work at: https://academicworks.cuny.edu/ny_pubs/433

Discover additional works at: https://academicworks.cuny.edu

This work is made publicly available by the City University of New York (CUNY).

Contact: AcademicWorks@cuny.edu 


\title{
2017 Proceedings st. Petersburg, Florida
}

\author{
An Examination of "Lookism" in Scholarly Literature \\ Diana Saiki, Ball State University, USA \\ Alyssa Dana Adomaitis, The New York College of Technology, CUNY, USA \\ Jessica Gundlach, Ball State University, USA
}

Key words: Lookism, Appearance, Literature, Discrimination

Key words: Lookism, Appearance, Literature, Discrimination

Significance/usefulness of the research/scholarship: Application of relevant theory or framework and pertinent literature: "Lookism" is a term to describe appearance discrimination or "the practice of discrimination on the basis of physical appearance in the workplace" (Ghodrati, Joorabchi, \& Muati, 2015, p.1). In popular literature, it has been called "beauty prejudice" (Etcoff, 1999, p. 1). The notion that a pleasing appearance results in favorable outcomes (e.g., higher wages, promotions) from others is not necessarily new, as literature on physical attractiveness is rather extensive. The Washington Post Magazine first used the term "lookism" in 1978 (e.g., Ayto, 1999). However, the term "lookism" was first recognized as a form of discrimination by authors of the Oxford English Dictionary and American Heritage Dictionary in 2000 (Ghodrati et al.).

There can be social injustices due to physical appearance; whether physically attractive or unattractive. Rhodes (2010) discussed the cultural injustices of being unattractive in an appearance obsessed society with the potential for "looks" to influence hiring practices, career options, and amount of pay. Those who feel unattractive in an appearance laden society could suffer certain mental health issues potentially causing anxiety, anorexia, and depression. Research is needed with regards to how lookism is defined and has been examined to combat the issue. The aim of this paper is to examine scholarly literature to identify how lookism has been defined and studied.

Methods/exploration techniques: A qualitative theme and content analyses were used to assess scholarly literature on lookism. Characteristics examined included: i) year published, ii) type of publication, iii) author's field of study, iv) context of lookism (e.g. workplace), v) definitions of lookism, vi) sample characteristics (e.g. geographic region, gender, age), and vii) instrument/s used. Scholarly articles were obtained through a search in google scholar and a university database. On google scholar only articles with "lookism" in the title were selected, and the university database scholarly works were found by searching for "lookism" in the title and abstract. The articles were analyzed by two researchers for interrater reliability $(98 \%)$.

Results: The search resulted in 43 scholarly works with $36^{1}$ written in English. From the 36 scholarly works analyzed, there were $10(27.8 \%)$ refereed journal articles reporting traditional research, eight (22.2\%) position or discussion journal article papers, six (16.7\%) student honor theses, five $(13.9 \%)$ book chapters, and three (8.3\%) conference abstracts. There were four (11.1\%) other forms of scholarships, such as briefs, a blog, and book reviews. Most articles were written by authors in business $(\mathrm{n}=18 ; 50 \%)$. Other fields mentioned were social sciences including sociology and

\footnotetext{
${ }^{1}$ A complete reference list of scholarly works examined will be provided at the presentation.
} 
communication $(\mathrm{n}=5 ; 13.9 \%)$, education $(\mathrm{n}=4 ; 11.1 \%)$, law $(\mathrm{n}=2 ; 5.5 \%)$, and women's studies $(\mathrm{n}=$ $2 ; 5.5 \%)$. Five (13.9\%) authors' backgrounds were not known.

The main context where lookism was examined was in the workplace $(n=20 ; 55.5 \%)$. Industries identified were public relations, hotel and retail, sports (NFL), service work, fitness industry, and academia. Lookism was examined in general society and within the law $(n=7 ; 20.4 \%)$. Other places lookism was examined were middle and high school, literature, within art works, and in the criminal system. Most articles focused on situations in the United States. However, other geographical regions noted were Finland and Scotland, U.K., Korea, China, and Indonesia. Two articles focused on globalization discussing several countries. Two (5.5\%) were published in the 1990s, 12 (33.3\%) from 2000-2009, and 25 (69.4\%) from 2010 - present.

Many authors provided a definition of lookism $(n=32)$. The authors discussed discrimination given an individual's "appearance," "looks," "beauty," "attractiveness", and "aesthetics." Specific visible demographic characteristics of the victim of these bias included weight, age, gender, race, style, grooming, hygiene, hair colour and texture, facial features, and clothing. An alternative phrase associated with lookism was "Aesthetic Labour" ( $\mathrm{n}=3 ; 9.4 \%)$. Discussions of lookism varied in degrees of moral ethics from a cultural standard, bias to prejudice, and discrimination. Seventeen (53.1\%) noted perceptions of various forms of lookism were bound by culture and relative to the target population. Discrimination was the most common word used to define lookism $(n=31$; 96.8\%) with one article labelling it a "crime."

Ten scholarly works discussed a research method, with all published after 2000 and eight (80\%) published after 2009. A range of methods were used to measure lookism, including qualitative questioning $(n=3 ; 30 \%)$, analysis of images and videos $(n=4 ; 40 \%)$, Likert scale $(n=2 ; 20 \%)$, and analysis of demographics of pre-existing court cases/documents $(\mathrm{n}=1 ; 10 \%)$. Body size and face symmetry were the primary measure for two studies. Another study compiled a variety of physical features including height, weight, eye colour, scars, face symmetry, tattoos, and body type. To measure discrimination salaries and punishments for crimes were used. Lookism tendencies and beliefs were measured through Likert scale and qualitative questioning. Only four (40\%) used a U.S. sample. The other studies incorporated samples in Sydney, European Union, and Indonesia. All studies found lookism existed, with all but one (90\%) noting better looking individuals receive favourable treatment. In one study, better looking criminals received more stringent punishment.

Discussion and Conclusions: Examining the scholarly literature on lookism suggests it: i) is an emerging concept in scholarly literature; ii) is a form of discrimination, particularly in the workplace; ii) includes a variety of physical features (e.g. age, facial symmetry, tattoos); iii) is multicultural; iv) supports popular literature that these biases exist (e.g., Ayto, 1999), and v) needs to be studied further to fully understand and define it.

Lookism is a significant topic (Rhodes, 2010), and apparel and textile (AT) researchers can utilize their expertise to examine it further. Specifically, the term "lookism" could be defined in more detail to include certain physical features and legal standards. For example, to define the ethical parameters of lookism, AT researchers could interview business executives or lawyers. The workforce is a common place to examine lookism, but other social settings could be studied. AT scholars could seek to provide a reliable and valid measure of lookism. Finally, additional articles on lookism could be examined using terms found in this study (e.g., aesthetic labour).

Page 2 of 3

○ 2017, International Textile and Apparel Association, Inc. ALL RIGHTS RESERVED ITAA Proceedings, \#74 - www.itaaonline.org 
Ayto, J. (1999). Twentieth century words. New York: Oxford University Press.

Etcoff, N. (1999). Survival of the Prettiest. New York: Anchor Books

Ghodrati, Z., Joorabchi, T., \& Muati, A. (2015). The influence of globalization on "Lookism" in workplace environment of different cultures. Global Media Journal, 13, 1-18

Rhodes, D. L. (2010). The Beauty bias: The injustice of appearance in life and law. New York: Oxford University Press. 